\title{
Correction to: An appraisal of critical effect sizes for the benchmark dose approach to assess dose-response relationships in genetic toxicology
}

\author{
Andreas Zeller $^{1}\left[\right.$ - Gonzalo Duran-Pacheco ${ }^{1} \cdot$ Melanie Guérard $^{1}$
}

Published online: 11 November 2017

๑) Springer-Verlag GmbH Germany, part of Springer Nature 2017

\section{Correction to: Arch Toxicol}

https://doi.org/10.1007/s00204-017-2037-3

In the original publication, Table 1 was incorrect (differences in the numerators of the fractions). The correct version of Table 1 (sums in the numerators) is given below.

Table 1 Formulas used to estimate CES

\begin{tabular}{|c|c|c|c|}
\hline $\mathrm{Nr}$ & Name & Formula & Data \\
\hline 1 & CESISD $_{\text {study }}$ & $\frac{\bar{x}+\mathrm{sd}}{\bar{x}}-1$ & Mean and standard deviation (sd) of the concurrent study \\
\hline 2 & $\mathrm{CESISD}_{\mathrm{hc}}$ & $\frac{\bar{x}_{\mathrm{hc}}+\mathrm{sd}_{\mathrm{hc}}}{\bar{x}_{\mathrm{hc}}}-1$ & Mean and sd of all historical control (hc) data in a lab \\
\hline 3 & $\mathrm{CESISD}_{\text {thc }}$ & $\frac{\bar{x}_{\mathrm{thc}}+\mathrm{sd} \mathrm{d}_{\mathrm{thc}}}{\bar{x}_{\mathrm{thc}}}-1$ & Mean and sd of he data after excluding the uppermost $5 \%$ data points (trimmed mean and sd) \\
\hline 4 & CESIMAD $_{\mathrm{hc}}$ & $\frac{\tilde{x}_{\mathrm{hc}}+\mathrm{mad}_{\mathrm{hc}}}{\tilde{x}_{\mathrm{hc}}}-1$ & Median and median absolute difference of all he data \\
\hline 5 & $\mathrm{CESISD}_{\mathrm{WBhc}}$ & $\frac{\tilde{x}_{\mathrm{hc}}+\mathrm{sd}_{\mathrm{WBhc}}}{\tilde{x}_{\mathrm{hc}}}-1$ & $\begin{array}{l}\text { Based on all hc data. } \mathrm{sd}_{\mathrm{WBhc}} \text { depends on the within and between study variances: } \\
\mathrm{sd}_{\mathrm{WBhc}}^{2}=\mathrm{sd}_{\mathrm{within}}^{2}+\mathrm{sd}_{\text {between }}^{2}\end{array}$ \\
\hline
\end{tabular}

The original article can be found online at https://doi. org/10.1007/s00204-017-2037-3.

Andreas Zeller

andreas.zeller@roche.com

1 Pharmaceutical Sciences, pRED Innovation Center Basel,

F. Hoffmann-La Roche Ltd, Grenzacherstrasse 124,

4070 Basel, Switzerland 